\title{
An Analysis of the Possibility of Using Coal Technologies to Improve Manoeuvrability, Mobility and Ecological Compatibility of Thermal Power Plant Units
}

\section{Introduction}

Ukraine's energy needs are ensured generally by operation and electricity generation of hydroelectric power plants (HPP), thermal (TPP) and nuclear (NPP) power plants. Among the above listed objects of major power engineering, thermal power engineering is the most dangerous in terms of ecology. Besides, it is most often used to cover peak loads, and in such modes its environmental hazard increases.

Manoeuvrability and mobility of thermal power stations can be increased by combining conventional steam turbine generating method and gas turbine cycle. Moreover, refusal to use expensive gas turbine fuel and so called "clean coal technologies" for operation of the gas section of combined cycle gas turbine plant can significantly improve not only technical and economic performance, but also significantly reduce anthropogenic load on the environment and increase overall efficiency rate of power unit.

\section{Statement of the Problem}

It was in the last century (1944) that German inventors proposed to use smoke [1] fumes for gas turbine operation obtained during burning of ground coal, which were pre-cleaned from solid particles (ash, unburned particles of fine coal dust). However, the presence of the abovementioned solid particles in smoke fumes leads to rapid deterioration of gas turbine blades, which makes this option uneconomical and of little use.

The widespread use of combined cycle plants is limited by high price of fuel for gas section, and combined cycle plants are characterized by emission into

\footnotetext{
* Ivano-Frankivsk National Technical University of Oil and Gas, Ukraine

** National University "Lviv Polytechnic", Ukraine
} 
environment of huge amount of harmful substances by typical steam section of a power unit. Among these according to magnitude of total emissions and hazard class, as well as impact on atmosphere and climate change, are nitrogen oxides. Detailed analysis of joint work of combined cycle turbine plants, carried out by authors [2] showed that together with improved efficiency of thermal energy conversion into electrical, there are significant environmental achievements on the major power engineering objects.

\section{An Analysis of the Options for Solving This Problem}

The authors have proposed a very different technical solution of this problem, the essence of which is in use of two (three) stage burning of low-grade coal. Thus at an early stage an additional cyclone furnace is used, in cooling jacket [3] of which the operating environment is formed (heated and prior compressed atmospheric air) for gas turbine operation. Flows of coal dust can be reallocated (some go into additional cyclone furnace and into the boiler unit, the rest go into boiler unit bypassing the additional furnace. Schematic block diagram of the proposed power plant is shown in Figure 1.

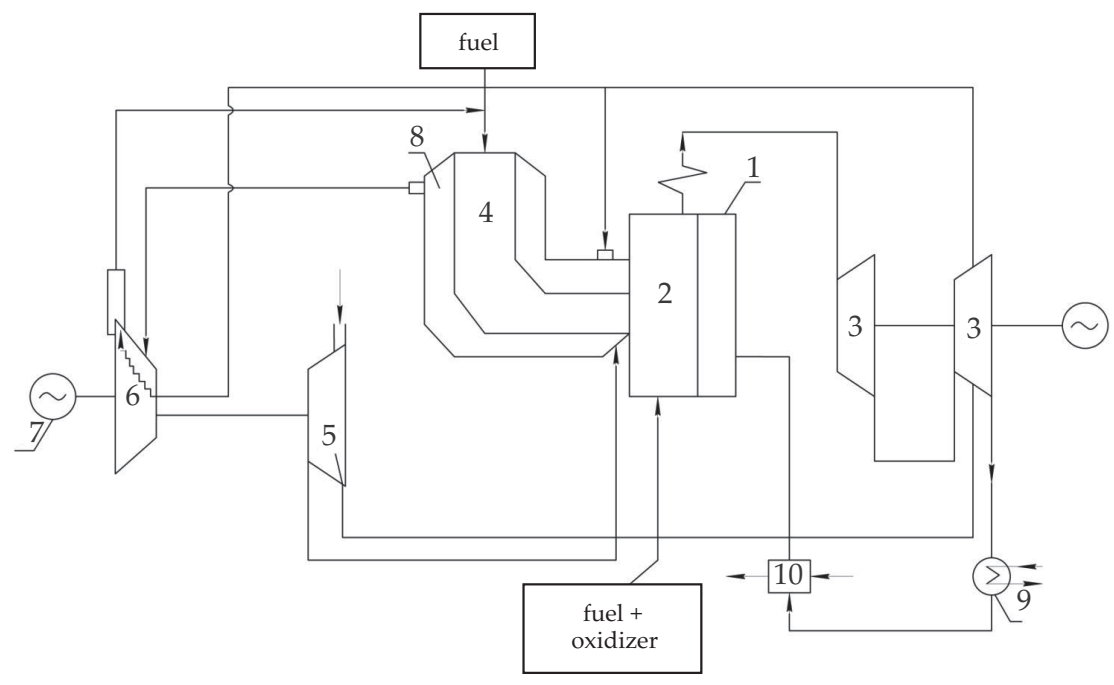

Fig. 1. Schematic block diagram of the power plant with an additional cyclone furnace:

1 - boiler unit, 2 - the main furnace, 3 - steam turbine, 4 - additional cyclone furnace,

5,6 - first and second stage of compressor, 7 - power generator of combined cycle plant, 8 - cooling jacket of cyclone prior furnace, 9 - steam cycle condenser, 10 - water heater 
In case of ground coal burning in a furnace of a boiler unit of combined cycle plant, especially of pretty low grade, or natural gas burning in normal mode (i.e. submitting required amount of atmospheric air in some abundance, which is defined by constructive characteristics of burners, the amount of nitrogen oxides formation, formed from atmospheric nitrogen does not decrease, but rather increases due to significantly higher temperature in the flare.

When serving oxygen enriched atmospheric air, in the burning zone, the total gross emission volume decreases due to less amount of atmospheric air as well as concentration of nitrogen oxides through much lower amount of atmospheric nitrogen. This fact is well known in the metallurgy and is widely used as "oxygen blow."

Research papers of many domestic and foreign scientists are devoted to methods of reducing nitrogen oxides in smoke fumes. Analyzing their results it can be stated that the formation of nitrogen oxides depends on the following factors: design of burners, abundance of atmospheric air, high flare temperature and time which fuel and oxidizer spend in burning zone.

When using oxygen enriched atmospheric air the last factor in formation of nitrogen oxides becomes less important. Schematic diagram of a power plant with a membrane air separator is shown in Figure 2.

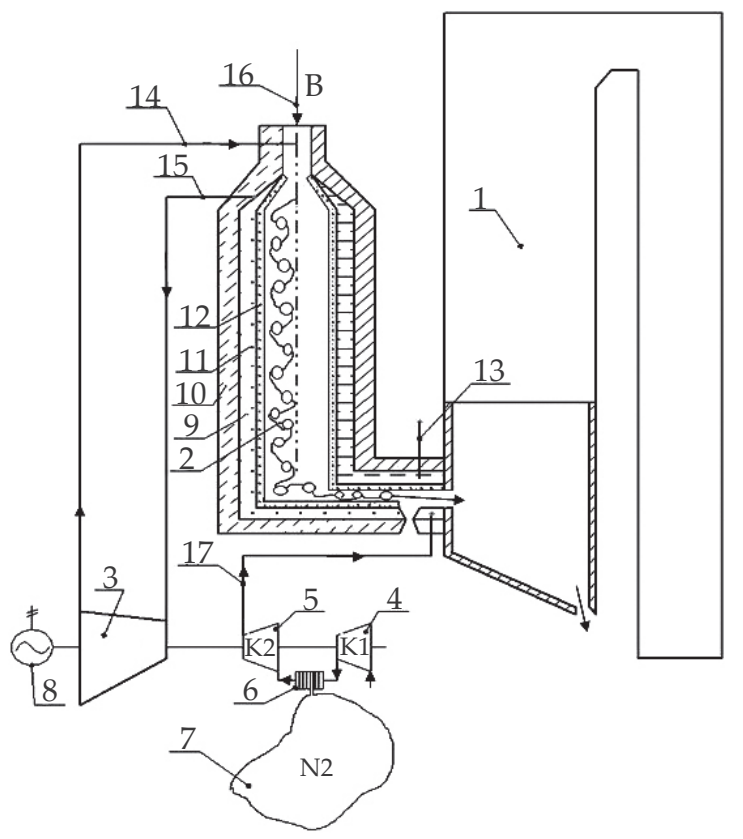

Fig. 2. Scheme of combined cycle plant with membrane air separator: 1,2-master and additional furnace, 3 - gas turbine, 4,5-first and second degree of compressor, 6 - membrane air separator, 7 - gasholder - nitrogen storage, 8 - electric generator of gas section, 9 - additional furnance cooling cavity, 10 - thermal isolation, 11 - heat pipe, 12 - additional internal furnace wall, 13 - steam injection line, 14 - exhaust duct for a gas turbine, 15 - working fluid cycle gas

pipe, 16 - fuel supply line to the auxiliary furnace, 17 - oxygen-enriched air supply line 
Taking into account the fact that there is a tendency in deterioration of coal quality and that atmospheric nitrogen is a source of oxides formation, future nitrogen oxide emissions will only increase.

Inventors [4] proposed a power plant with membrane air separator which provides not only high manoeuvrability and mobility of a power unit, but also significant reduction of nitrogen oxides emissions due to the lack of sufficient raw materials for their formation.

The need for a transfer of major power engineering on the combined cycle power plants for increased mobility to cover peak loads and strict environmental requirements to the power plants, and on the other hand - high price of gas turbine fuel (gaseous or liquid) and deterioration of steam coal quality set in front of modern scientists dual and mutually exclusive task.

\section{Conclusions}

The set problem can be efficiently solved in the following way:

- transfer of gas section of combined cycle gas turbine plant on solid fuel,

- burning more low grade coal to reduce environmental hazards without significant decline in technical and economic performance of a single unit.

The solution of this problem can be implemented using the latest achievements in science and technological innovations of world known manufacturers.

In our opinion, the problem is solved by replacing gaseous or liquid, and the same time expensive gas turbine fuel with a product that is heated by products of combustion (smoke fumes). This can be done using a two-stage (or a three stage) burning of low grade solid fuel. Thus, the operating environment in cooling jacket of additional cyclone furnace is heated for gas turbine.

\section{References}

[1] Combined cycle thermal power plant. Patent of FRG 839290, 1944.

[2] Semchuk Ya.M., Kulyk M.P.: Ekolohichni ta tekhniko-ekonomichni aspekty spil'noyi roboty paro- $i$ hazoturbinnykh enerhetychnykh ustanovok. Naftohazova enerhetyka: vseukr. nauk.-tekhn. zhurn, no. 1 (6), 2008, pp. 65-68.

[3] Grinchenko D.N., Kulik M.P.: Sposob raboty energeticheskoy ustanovki. Author's certificate of USSR no. 1188338, BV no. 40, 1985.

[4] Pen'kov V.I., Hrinchenko D.M., Kulyk M.P.: Enerhetychna ustanovka. Patent of Ukraine no. 18 856, BV no. 6, 1997. 